\title{
El patrimonio cultural en los servicios turísticos de la provincia de Manabí, Ecuador.
}

\section{Dallas Glenda Hormaza Muñoz* Roberto Manuel Torres Rodríguez** Universidad Laica "Eloy Alfaro" de Manabí (Ecuador)}

\begin{abstract}
Resumen: El desarrollo turístico está estrechamente ligado a la gestión del patrimonio cultural de las comunidades, tanto el material como el inmaterial. La investigación resuelve el problema de la estimación que se le dé al uso de los valores del patrimonio cultural en los servicios turísticos en Manabí, Ecuador. El objetivo es diagnosticar la puesta en valor del patrimonio cultural en la gestión del producto turístico manabita por los diferentes actores involucrados en la gestión del patrimonio cultural. Se realizó una amplia búsqueda bibliográfica y una investigación descriptiva, de campo, con énfasis en lo cualitativo, se utilizaron las técnicas de la encuesta y la entrevista en lo fundamental. Se empleó una encuesta con muestreo por cuotas, buscando valorar el objeto de investigación desde diferentes perspectivas por grupos estrechamente relacionados con este, pero que tienen roles diferentes en cuanto a su gestión. El principal resultado da la evidencia de la riqueza y la diversidad de la cultura manabita con alto valor patrimonial y comercial como recurso turístico.
\end{abstract}

Palabras Clave: Cultura; Patrimonio cultura; Turismo cultural

The cultural heritage in tourist services in the province of Manabí, Ecuador.

Abstract: Tourism development is particularly closely linked to the management of communities' tangible and intangible cultural heritage in Ecuador. This research solves the problem of evaluation of the use of cultural heritage values in tourism services in Manabí, Ecuador. The objective is to diagnose how cultural heritage can offer added value to tourism in Manabí as seen by the various people involved in cultural amangement. An extensive bibliographical review and a descriptive field research were carried out, with emphasis on the qualitative aspects of heritage, using mainly surveys and interviews. A survey with quota sampling was used to assess the research from different perspectives by groups closely related to cultual heritage, but with broadly different roles in terms of management. The main results show the wealth and diversity of the Manabí culture with its excellent heritage, of great commercial value as a tourist resource.

Keywords: Culture; Cultural heritage; Cultural tourism.

\section{Introducción}

Los valores ancestrales, las tradiciones y el patrimonio se entrelazan en un concepto más general que es el de cultura.

Según Molano (2007), la cultura es el conjunto de todas las formas, los modelos o los patrones, explícitos o implícitos, a través de los cuales una sociedad regula el comportamiento de las personas que la conforman. Como tal incluye costumbres, prácticas, códigos, normas y reglas de la manera de ser, vestimenta, religión, rituales, normas de comportamiento y sistemas de creencias. Desde otro punto de vista se puede decir que la cultura es toda la información y habilidades que posee el ser humano (Molano, 2007).

La UNESCO en la Declaración de México de 1982 en la conferencia mundial sobre políticas culturales, define la cultura como todo lo complejo que incluye el conocimiento, las creencias, el arte, la moral, el derecho, las costumbres y cualesquiera otros hábitos y capacidades adquiridos por el hombre como

\footnotetext{
* Universidad Laica "Eloy Alfaro” de Manabí (Ecuador); E-mail: dallasglenda@gmail.com

** Universidad Laica "Eloy Alfaro” de Manabí (Ecuador); E-mail: robertomanueltorres62@gmail.com
} 
miembro de la sociedad. Es el conjunto de los rasgos distintivos, espirituales, materiales y afectivos que caracterizan una sociedad o grupo social. Ella engloba, además de las artes y las letras, los modos de vida, los derechos fundamentales del ser humano, los sistemas de valores, creencias y tradiciones.

El término cultura tiene varias acepciones conceptuales, desde diferentes disciplinas y dentro de cada una de ellas presenta diferentes enfoques teóricos. Considerando el punto de vista antropológico, de manera general, se entiende por cultura las prácticas materiales y de significación, al mismo tiempo, de continua producción, reproducción y transformación de las estructuras materiales y de significación que organizan la acción humana. (Vera Noriega y Rodríguez Carvajal, 2009)

La herencia social es el concepto clave de la antropología; y, específicamente en el concepto de cultura, que incluye los artefactos, bienes, procedimientos técnicos, ideas, hábitos y valores heredados. La cultura no es un fenómeno material: no consiste en cosas, gente, conductas o emociones, es más bien, un sistema de interrelaciones entre los procesos individuales ontogenéticos, los sociales, que abarcan el comportamiento colectivo en un corte de tiempo y los antropológicos que hacen posible los productos culturales, incluyendo a las manifestaciones artísticas, cotidianas, científicas, tecnológicas y las de tipo folklórico. (Ibídem)

Barrera Luna (2013), ve como una definición útil de la Cultura al conjunto de modos de vida y costumbres, conocimientos, grado de desarrollo artístico, científico, industrial, en una época o grupo social, útil para definir ese todo que se percibe y se contempla sin llegar a saber correctamente qué es.

Como se aprecia en las definiciones de cultura se integran costumbres, hábitos y todo el patrimonio material e inmaterial al que la sociedad le da valores y significación social, y que considera necesario preservar en el tiempo.

La tradición equivale al concepto de cultura como la conciben los antropólogos: un sistema integrado dialécticamente por subsistemas interrelacionados: lo material (infraestructura: las relaciones que se establecen entre los hombres y el medio), lo conductual-social (la estructura: las relaciones que construyen y mantienen los hombres y las mujeres entre sí) y lo mental-simbólico (la superestructura: las relaciones que se dan entre los hombres y el más allá, lo sobrenatural) De tal manera la tradición, vehículo de memoria, se adapta y recrea; porque la tradición por su característica de fluidez y permeabilidad vincula a la gente con su historia, es decir con la memoria colectiva (Arévalo, 2010).

Los bienes culturales materiales e inmateriales no pueden disociarse, todo lo material tiene un sustrato inmaterial. De hecho los objetos materiales son el resultado de los conocimientos, las normas y los valores que prevalecen en cada cultura y grupo social. Lo importante, entonces, no son tanto los productos como los procesos, es decir la transmisión del conocimiento, antes que la conservación de los objetos (Ibídem)

\section{Valor patrimonial}

El patrimonio, desde la perspectiva social, es parte de la historia y de la esencia de la cultura, es la síntesis simbólica de la identidad de una región o nación; esto implica un proceso de reconocimiento como parte del sentido de pertenencia a un grupo o territorialidad y su distinción en el contexto universal. El patrimonio es una herencia, un legado de las generaciones pasadas que debe ser conservado y protegido a favor del presente y de generaciones futuras. En este contexto, el patrimonio es un concepto en sí mismo que alude a la historia y que hace parte esencial de la cultura. El patrimonio es considerado por muchos como la síntesis simbólica de los valores identitarios de una sociedad que los reconoce como propios. (Bucheli y otros, 2009)

El patrimonio, una especie de simbología social para el mantenimiento y la transmisión de la memoria colectiva, está constituido por los bienes representativos de cada sociedad. Y se puede afirmar que los fenómenos patrimoniales revisten una triple dimensión: física, social y mental; es decir, material y simbólica (Arévalo, 2010).

En el comercio, es posible medir el valor de los objetos que se encuentran a la venta en términos de su precio; lo mismo ocurre con obras de arte y con antigüedades cuando se ofrecen en el mercado. El valor de mercado de un objeto no es el mismo que su valor patrimonial, estos conceptos se basan en parámetros diferentes. En cuanto a los objetos de patrimonio, más que proponer medir los valores patrimoniales, parecería más apropiado evaluar el impacto de su reconocimiento (Jokiletho, 2016).

Los valores culturales incluyen el valor de identidad, que es la asociación emotiva de individuos o de una comunidad a un objeto o un lugar. Un recurso patrimonial puede ser apreciado por su valor histórico-artístico o técnico-histórico relativo, cuyo reconocimiento se fundamenta en la investigación de profesionales, o se puede reconocer el valor de su rareza, que está parcialmente basado en la investigación histórica y que también es reconocido por la administración responsable de la protección de los bienes patrimoniales. 
Además, los recursos patrimoniales están también asociados con valores socioeconómicos contemporáneos, incluyendo por ejemplo los valores funcionales, los valores educativos, los relacionados con el turismo, los valores sociales, y los valores políticos relacionados con las prioridades del régimen en particular (Ibídem).

La formación en valores, como proceso cultural y educativo, potencia usufructuar y salvaguardar la diversidad cultural y las expresiones producidas por las sociedades, así como impulsar que los ciudadanos construyan conocimientos humanísticos significativos, consoliden sus identidades nacionales. Se consideran tres las formas en que los ciudadanos adoptan valores sociales: valores heredados; valores desarrollados en educación formal; valores desarrollados en educación no formal. La educación se considera como el medio para la transmisión y el intercambio de valores, así como por inducir la humanización de los individuos, es el vehículo que debe utilizarse para socializar y asegurar la permanencia del patrimonio (Peña Palma, 2013 y Cartagena, 2017)

El concepto de patrimonio se ha extrapolado y aplicado a otras disciplinas, sin perder su esencia básica, que se encuentra en su definición legal y económica: es un cúmulo de bienes o propiedades heredados por una persona y que son libres de vender o trasmitir. Tal es el caso de las ciencias sociales modernas, en donde aparece el término patrimonio cultural, significando entonces ese cúmulo de cosas culturales o naturales que pertenecen a una comunidad entera. El patrimonio cultural es un cúmulo de bienes culturales que se heredan en colectividad, son aquellos productos culturales tangibles o intangibles que tienen un valor excepcional para un grupo social determinado y que forma parte fundamental de su identidad cultural (Ramos, 2017).

El patrimonio cultural es una categoría de clasificación de objetos socialmente construida, es decir que, la patrimonialidad no proviene de las características intrínsecas de los objetos sino de las consideraciones e intereses que tengan los sujetos sobre estos, su selección para que formen parte del patrimonio cultural está condicionada por el valor y reconocimiento que le otorgue la sociedad en un contexto determinado y se considera esencial su herencia, su protección y su conservación (Ibídem).

Todo patrimonio es producido mediante un proceso dialéctico de objetivación y subjetivación de valor. El enfoque dialéctico evita, por un lado, la equiparación de la capacidad de agencia de las cosas con la de las personas, por otro lado, evita la minusvaloración de los efectos sociales de los objetos y su reducción a meros artículos de consumo (el patrimonio como espectáculo). Salvo en los libros de texto y manuales escolares, donde la temática de la conservación y sus problemas sigue ausente incluso en los más recientes, el resto de los análisis revelan que el valor de legado ha ido adquiriendo cada vez mayor presencia en los diferentes medios, así como en la opinión de los agentes (Barreiro y Criado-Boado, 2015).

El patrimonio está supeditado a cuestiones históricas y sociales, y es inseparable de la concepción relativista de la sociedad y la cultura. Por lo tanto, la importancia cultural de un objeto se asocia con los significados que la sociedad identifica en éste. Los significados que le hagan sentido sólo a un grupo limitado de personas no serán importantes como referencias para la conservación institucional del patrimonio. Los significados relevantes de este proceso son aquellos que le dan sentido a colectividades o a amplios grupos sociales (Mendes Zancheti, 2016).

El patrimonio no es un producto de la sociedad, es parte de la sociedad, vive y cambia con ella, así mismo no existe un solo patrimonio, las lecturas y percepciones del mismo son infinitas, diferenciadas no solo en el espacio sino también en el tiempo (Erice, 2017).

En todo proceso de valoración de un bien u objeto patrimonial, sucede que el valor de cualquier bien estará dado por una combinación de las valoraciones de los distintos individuos que se relacionan con éste y todo bien contiene ciertos elementos objetivos de valoración expresados en variables definidas y eventualmente parametrizadas (historia, formas constructivas, valores estéticos, etc.) y valores subjetivos donde la asignación de valor responde a una serie de factores sociales, perceptivos o de significación social y no asociados a una dimensión técnica ni a estándares paramétricos de evaluación (Peña Galvés, 2010).

La medición de los valores se expresa quizá más apropiadamente en términos de monitoreo de sus impactos. Los valores son productos de procesos de aprendizaje y no deberían confundirse con el valor de mercado o precio de mercado de un objeto en particular. Como resultado, más que intentar medir el valor del patrimonio, será más apropiado evaluar el impacto. Los valores generados por el público en general, los profesionales y los responsables son componentes de los valores públicos o valores compartidos, que forman la base de las políticas de protección del patrimonio (Escribano Velasco, 2010 y Jokiletho, 2016).

Los bienes culturales, tangibles o intangibles, no son residuos de un tiempo pasado que hay que conservar en un supuesto modelo ideal. El patrimonio intangible está en todos los aspectos de los bienes culturales. Y es la base de la identidad, la creatividad y la diversidad cultural. Es un patrimonio vivo, continuamente recreándose, que cobra vida a través de los seres humanos y de sus prácticas y formas de expresión (Arévalo, 2010). 
Definir qué consideramos valioso constituye el primer paso en la planificación de la gestión patrimonial y gestión territorial y, cada vez más, se insiste en el valor patrimonial, contemplado y avalado desde lo que supone el marco biofísico o medio natural y también lo que significa la huella que el hombre ha ido dejando en ese marco biofísico a lo largo de la historia, pues ambos valores son los que singularizan y distinguen al paisaje (Criado-Boado y Barreiro, 2013 y Tudela Serrano, 2015).

El tema cultural es tratado desde varios aspectos: el económico, donde la cultura se vincula al mercado y al consumo y se manifiesta en las llamadas industrias culturales (empresas editoras, casas de música, televisión, cine, etc.); el humano, donde la cultura juega un papel de cohesión social, de autoestima, creatividad, memoria histórica, etc.; el patrimonial, en el cual se encuentran las actividades y políticas públicas orientadas a la conservación, restauración, puesta en valor, uso social de los bienes patrimoniales, etc. Se podría decir que la cultura tiene varias dimensiones y funciones sociales, que generan: un modo de vivir, cohesión social, creación de riqueza y empleo y equilibrio territorial (Molano, 2007).

La identidad no es un concepto fijo, sino que se recrea individual y colectivamente y se alimenta de forma continua de la influencia exterior. La identidad sólo es posible y puede manifestarse a partir del patrimonio cultural, que existe de antemano y su existencia es independiente de su reconocimiento o valoración. El desarrollo de un territorio supone una visión que pasa por una acción colectiva, que involucra a los gobiernos locales, regionales, el sector privado y la población en general. Y esta acción colectiva implica numerosas actividades que pueden basarse en lo cultural, como la identidad y el patrimonio. El valorar, restaurar, proteger el patrimonio cultural es un indicador claro de la recuperación, reinvención y apropiación de una identidad cultural (Ibídem).

El patrimonio cultural es fuente de unidad y desarrollo de una comunidad o grupo social, su puesta en valor da vida y sostenibilidad a la identidad cultural y al territorio.

\section{Uso turístico del patrimonio}

En los servicios, el caso del turismo tiene una particular relación histórica con el patrimonio. Se podría hablar de turismo cultural desde la época griega y romana, lo que actualmente se conoce como recorridos turísticos culturales aparecen con el Grand Tour (que duraba entre dos y tres años), que era la visita realizada por aristócratas ingleses a los lugares históricos, artísticos y naturales más destacados de Europa. En el siglo XIX aparecen las colecciones de guías de viaje y el concepto patrimonial abarca lo etnológico. En el siglo XX surge el turismo de masas y otras formas de turismo relacionado con lo patrimonial: ecológico, temático y activo y cultural (Molano, 2007).

El sector del turismo ha sido así considerado una vía idónea para potenciar la diversificación económica de los territorios afectados por el declive de las actividades económicas primarias o industriales. Según la Organización Mundial del Turismo, el 37\% de los viajes que se realizan en el mundo tienen por motivación principal el encuentro con la diferencia cultural a través del patrimonio (Troitiño, 2012).

En América latina, la creciente actividad del turismo cultural acelera y provoca cambios en las estructuras socioeconómicas y en el uso de los recursos patrimoniales como determinantes para el origen y motivación para el origen y motivación de los viajes (Arista Castillo, 2017).

La gestión turística en torno al patrimonio cultural que se desprende de este nuevo modelo de desarrollo ha sido definida por multitud de autores a lo largo de los últimos años, coincidiendo muchos de ellos en hacer alusión a una implementación de conocimientos específicos con el fin de otorgar uso turístico a aquellos bienes que conforman el patrimonio cultural (Albarrán Periáñez, 2017).

De este modo las diversas expresiones culturales se han integrado a la mayoría de los segmentos turísticos, generando nuevos nichos de mercado. Esta tendencia promovió el turismo cultural, que se constituye como una actividad creciente y altamente competitiva (Hiriart y Barrera, 2017).

El patrimonio cultural no debe convertirse en una simple mercancía al servicio del turismo, sino que debe establecerse una relación de apoyo mutuo. El patrimonio como factor generador de identidad es compatible con su valor en términos de recurso turístico. Hay que tratar de conjugar su valor de uso (marcador de la memoria colectiva) con el valor de mercado (producto cultural comercializable) y convertirlo realmente en un factor de desarrollo que contribuya a mejorar la calidad de vida de las gentes (Arévalo, 2010).

El patrimonio cultural, además de referente simbólico y seña de identidad de una sociedad, es una pieza relevante de la calidad y del atractivo del territorio. Por tanto, cultura, patrimonio y turismo deben manejarse de forma complementaria a la hora de perfilar proyectos de desarrollo territorial (Troitiño Torralba, 2015). 
La progresiva incorporación del patrimonio cultural al turismo de masas, de forma directa o indirecta, explicita la necesidad de una estrecha coordinación y complementariedad entre políticas urbanísticas, patrimoniales y turísticas. Los cambios en las demandas y las nuevas prácticas turísticas exigen apostar, de forma decidida, por la cualificación y diversificación geográfica de la oferta patrimonial. Con voluntad política y adecuados mecanismos de concertación y gestión, es posible perfilar estrategias de desarrollo, donde la dimensión turística se integre razonablemente en los planes de gestión patrimonial, y la dimensión patrimonial en los de desarrollo turístico (Ibídem).

El creciente interés de los gestores públicos por el turismo cultural, va unido al convencimiento de que se trata de un segmento con potencial desarrollo y un efecto económico positivo. En el contexto actual de crisis económica, la capacidad de los destinos turísticos en competir en los mercados, de acuerdo a sus recursos y capacidades culturales, les permiten sobrevivir. De esta manera el turismo cultural podría ser un generador de ingresos, tanto para las instituciones patrimoniales como para los operadores turísticos (Montero-Muradas y Ojeda-Rodríguez, 2014).

El interés por los temas y prácticas turísticas relacionados con el patrimonio histórico, artístico y monumental, mejor llamado patrimonio cultural se ha generalizado, lo que se explica a partir del aumento del nivel medio de formación de la sociedad y el acceso a la cultura que ha tenido lugar en las últimas décadas. A ello se unirían, las prácticas recreativas, donde la gastronomía toma un papel protagonista, así como la asistencia a festivales, manifestaciones artísticas y de vida nocturna, etc. La gestión turística no puede ser independiente de la cultural, de la urbana o de la de los servicios públicos si se quiere optimizar el resultado de cada una de ellas y aprovechar las sinergias que todas juntas desencadenan (Pastor Coello, 2014).

Los conceptos de Turismo y Cultura presentan una relación simbiótica en la que los dos componentes se complementan, pero al mismo tiempo, funcionan bajo lógicas y necesidades distintas, por tanto desde esta perspectiva el turismo es una oportunidad para poner en valor y aprovechar el patrimonio cultural, a la vez que genera recursos que coadyuvan a su conservación y desarrollo (Hiriart y Alvarado, 2013)

Patrimonio cultural y turismo son dos áreas de alto interés para la comunidad turística a nivel nacional e internacional, su relación determina los gustos y preferencias de los visitantes hacia sus destinos (Sandoval Guerrero, 2017). Y constituye una alternativa importante a los destinos de sol y playa (Hiriart y Alvarado, 2013).

En los últimos años asistimos a la multiplicación de rutas e itinerarios turísticos por todos los rincones del Planeta. En su diversidad, estos productos coinciden en poner en el mercado un territorio que, por sus características y valores presuntamente singulares, pretenden atraer la visita de consumidores potenciales (Hernández Ramírez, 2011).

En América Latina, la creciente actividad de turismo cultural acelera y provoca cambios en las estructuras socioeconómicas y en el uso los recursos patrimoniales como determinante para el origen y motivación de los viajes (Arista Castillo, 2017).

Un itinerario turístico es un recorrido temático propio de una comunidad o área geográfica, que permite el conocimiento de sus valores y atractivos más particulares, capaz de atraer visitantes y motivar su desplazamiento a lo largo de ella (Molina Ruiz, Tudela Serrano y Guillen Serrano, 2014).

De un lado, la creciente reflexividad social sobre la crisis del medio ambiente y de autenticidad de las culturas, que en el terreno de la práctica turística se manifiesta en un deseo cada vez más generalizado por conocer espacios naturales, sociedades singulares y bienes patrimoniales; y de otro, la expansión social del patrimonio que implica el surgimiento de nuevas categorías patrimoniales como las de paisaje como valor patrimonial e itinerarios culturales. Este es el contexto social, subyace la proliferación de rutas turísticas de todo tipo a escala global (Gómez-Ortiz y otros, 2010; Hernández Ramírez, 2011).

Como se puede observar en el análisis realizado, los valores patrimoniales y culturales son la base de los atractivos turísticos en la actualidad, donde se combinan en un territorio, zona o país para ser consumidos fundamentalmente como rutas o itinerarios. Por lo que se sustenta la idea de que los valores patrimoniales (Ancestrales, tradiciones, etc.), son un sustento fundamental de la competitividad de un destino turístico e imprescindible en los servicios turísticos.

\section{Contexto ecuatoriano}

En el Ecuador, el legado cultural evidenciado ha permitido la construcción de espacios de encuentro común que fortalecen la identidad nacional, la diversidad, la plurinacionalidad y la interculturalidad y a su vez permite la generación de nuevas fuentes de ingresos para las personas vinculadas, siendo estas una parte activa a la transformación de la matriz productiva. Estos nuevos enfoques y formas 
de relacionarse con el patrimonio (primero desde las instituciones directoras y después desde la sociedad-gobiernos, clero, empresas, sociedad civil), están generando entornos de trabajo para el sector (Sandoval Guerrero, 2017).

El turismo cultural en Ecuador se manifiesta con mayor fuerza en el turismo comunitario, definido como toda actividad turística solidaria que permite la participación activa de la comunidad desde una perspectiva intercultural y el manejo adecuado del patrimonio cultural, basado en un principio de equidad en la distribución de los beneficios locales, se ha convertido en una actividad estratégica para muchas comunidades rurales e indígenas del Ecuador (García Palacios, 2016).

El turismo comunitario en Ecuador tiene su fortaleza en la singularidad de las comunidades ecuatorianas con factores intrínsecos que propician el desarrollo del turismo comunitario, por ejemplo, las inteligencias colectivas como la minga. Una comunidad tiene significados comunitarios profundos relacionados con la revalorización de la identidad, la defensa del territorio, la mejora en la calidad de vida y la necesidad del fortalecimiento organizacional comunitarios (Rodas, Ullauri y Sanmartín, 2015). En este sentido se debe subrayar el manejo adecuado que es necesario dar a este patrimonio, por cuanto la patrimonialización y el afán de un turismo mal planteado, como si fuese la solución a todos los problemas de marginalización y pobreza de las comunidades indígenas puede tener implicaciones muy fuertes en la pérdida de los valores que han dado identidad a estas comunidades (Azebedo, 2015).

En la provincia de Manabí, entre otros destaca el patrimonio cultural arqueológico que da fe de las culturas chorrera, Jama-Coaque, Bahía, etc., la artesanía de paja toquilla (una variedad de palma denominada toquilla) y la tradición oral recreada por mitos y leyendas (Solórzano Venegas, 2016).

Por todo lo antes expuesto, en los actuales espacios laborales se reconoce al patrimonio cultural tangible e intangible como elemento facilitador de sinergias en el trabajo conjunto y colaborativo de los diferentes actores económicos, consiguiendo así resultados integradores y holísticos en favor de la salvaguarda del patrimonio cultural del país, el beneficio social y el desarrollo económico de los sectores relacionados.

El objetivo de la investigación se centró en diagnosticar el rol de los valores culturales patrimoniales en la atención al turista en el contexto actual de los servicios turísticos en la provincia de Manabí, Ecuador.

\section{Metodología}

Es una investigación descriptiva, de campo, con énfasis en lo cualitativo. Para su realización se empleó una encuesta con muestreo por cuotas buscando valorar el objeto de investigación desde diferentes perspectivas por grupos estrechamente relacionados con este, pero que tienen roles diferentes en cuanto a su gestión.

El contenido de la encuesta se estructuró en preguntas que utilizan una escala de Likert de cinco niveles para valorar, por los diferentes estratos (cuotas definidas) la atención al turista en Manabí y los valores ancestrales en esta. Se realizó un proceso de operacionalización de las variables fundamentales, del cual resultaron las variables: compromiso y preparación del personal que atiende al turista y la calidad percibida en dicha atención, el interés del turista y la promoción de los valores ancestrales culturales por los prestatarios del servicio turístico y la percepción que se tiene del rol que desempeña la cultura manabita y el gobierno local en la atención al turista en Manabí.

Los valores culturales son un pilar de primera importancia para el desarrollo del turismo en la comunidad, sin embargo el turismo y la cultura se gestionan por diferentes entes con roles, a veces muy distintos pero estrechamente vinculados entre sí, por ello se procedió a realizar un muestreo por cuotas, considerando para esto el nivel de importancia y participación en la gestión del objeto de investigación, así como su conocimiento y experiencia.

Cuotas seleccionadas: Gestores culturales (25), Funcionarios y gestores del turismo (25), Comunicadores sociales (25) y Turistas (36).

Como unidades de análisis en el caso de los turistas se escogieron los Hoteles Bahía Hotel y Hotel Buena Vista del cantón Sucre, Hostal Marlín de la Parroquia Crucita, cantón Portoviejo; y, Restaurant Gnomos de la Parroquia Sta. Marianita, cantón Manta, por sus categorías y aportes al sistema turístico de la provincia y su distinción en la atención al turista. Para el procesamiento de los datos de la encuesta se utilizará la tabla de frecuencias.

Se efectuaron entrevistas semiestructuradas a varios expertos (4) que se relacionan directamente con los estratos (cuotas) seleccionados para valorar desde sus perspectivas la situación actual de la problemática, en el caso de los funcionarios y gestores del turismo para conocer como evidenciar y lograr el compromiso y la preparación de los empleados en la atención al turista, cuáles son la preferencias de 
los turistas en cuanto a los valores culturales y la pertinencia de los proyectos gubernamentales en la puesta en valor del patrimonio cultural (valores ancestrales) en la atención al turista en Manabí. Las entrevistas fueron grabadas, las transcripciones y revisión corrió a cargo del entrevistador.

En el caso de los historiadores (2) y comunicadores sociales (2) para valorar desde sus perspectivas en cuanto a si los manabitas están comprometidos con el legado cultural heredado, si los actos públicos reflejan la investigación los valores ancestrales, la mejor manera de transmitir esos valores a niños y jóvenes, cuáles eran los elementos arquitectónicos que distinguían las viviendas manabitas, cuáles son las manifestaciones culturales que más se recuerdan.

También se entrevistaron personas consideradas ciudadanos ilustres (3) para conocer desde sus perspectivas cuáles son los valores y costumbres más importantes heredados de los abuelos manabitas, qué deberían contener de las raíces las manifestaciones culturales y qué debiera trasmitirse como enseñanza a las nuevas generaciones, qué ofrecer de acuerdo a las tradiciones de hospitalidad manabita a los visitantes, qué elementos deben destacar en las construcciones modernas, y cuáles son las manifestaciones culturales más arraigadas en su memoria. En el procesamiento de los datos de las entrevistas se procede de forma manual por el investigador utilizando los principios básicos de análisis de datos cualitativos.

\section{Resultados}

\subsection{Breve reseña de la provincia de Manabí, Ecuador.}

La provincia de Manabí es una de las 24 provincias del Ecuador, situada, situada al occidente del país, en la zona geográfica conocida como región Litoral o Costa. Ocupa un territorio de unos 19.427 km², siendo la cuarta provincia del país por extensión. Además pertenecen a la jurisdicción de la provincia la Isla de la Plata y la Isla Salango. Tiene una franja marítima a lo largo del océano Pacífico de unos 350 kilómetros. En Manabí habitan alrededor de un 1’369.780 personas en sus por 22 cantones, con sus respectivas parroquias urbanas y rurales. (Figura 1).

\section{Figura 1: Ubicación espacial de la Provincia de Manabí, Ecuador.}

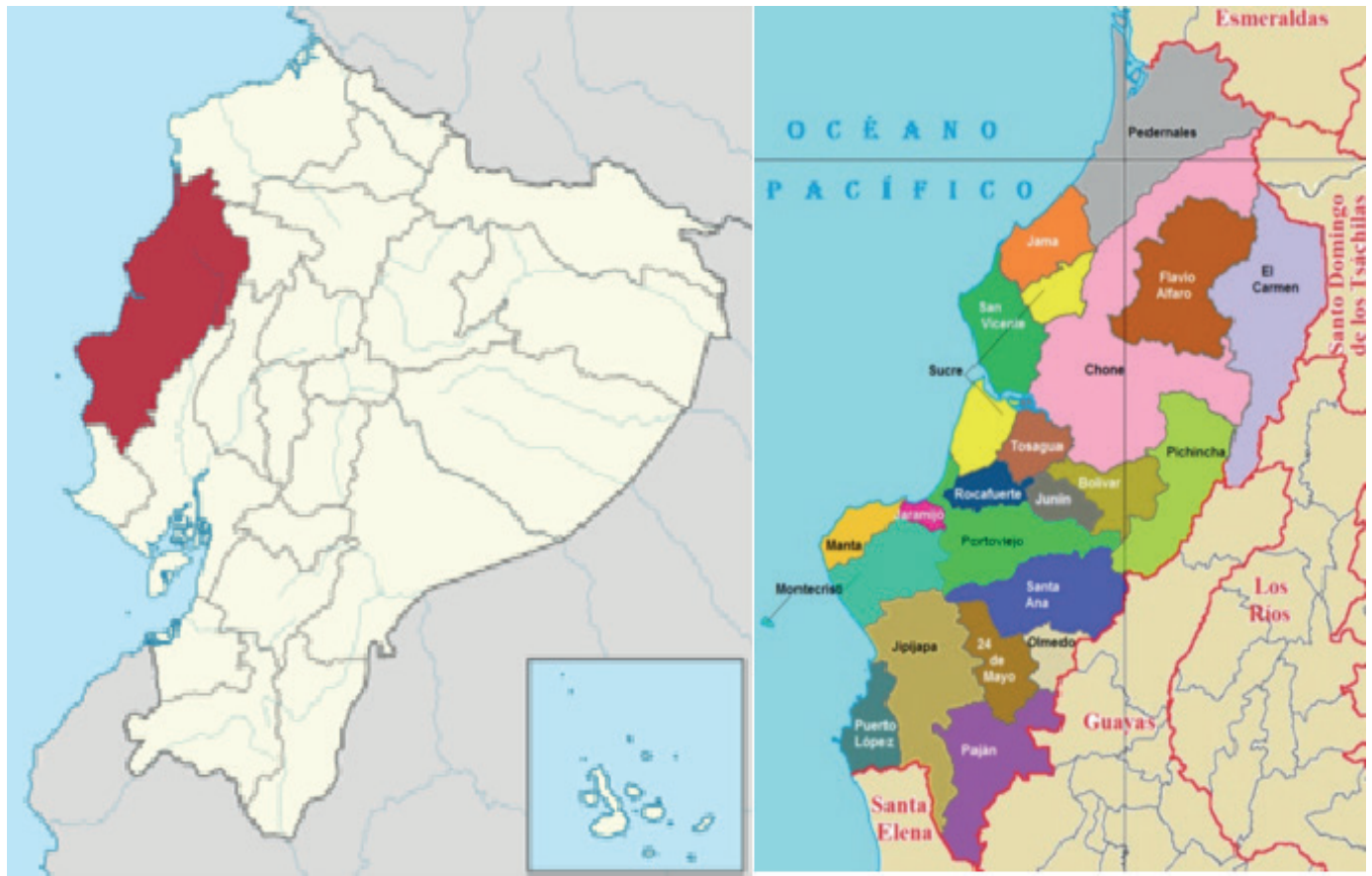

Fuente: Instituto geográfico Militar de Ecuador 
La provincia de Manabí presenta una amplia lista de patrimonios culturales y naturales, entre los que se destacan: el tejido tradicional del sombreo ecuatoriano de paja de toquilla en la comunidad Pile, perteneciente al cantón Montecristi, declarado Patrimonio de la Humanidad el 5 de diciembre de 2012; el parque nacional de Machalilla, un ben mixto propuesto por el Ecuador para patrimonio de la humanidad; la Cocina manabita declarada patrimonio cultural inmaterial del ecuador el 18 de octubre de 2018; la ciudad de Jipijapa, patrimonio cultural nacional el 15 de junio de 2017; el parque central de Portoviejo en la capital de la provincia, la torre del reloj de Calceta, la Casa de los abuelos ubicada en el cantón Santa Ana, una construcción de caña y madera construida entre los años 1880 y 1890; la reserva ecológica Mache-Chindul ubicada en el cantón Pedernales; la playa Los Frailes ubicada en el parque nacional Machalilla; sitio santuario Cerro de Jaboncillo y Cerro de hojas perteneciente e la cultura manteña y ubicado en las cercanías de Portoviejo la capital provincial; el museo Eloy Alfaro de Montecristi y los Amorfinos como una de las representaciones más genuinas de los saberes tradicionales de Manabí, todos ellos declarados patrimonio nacional. Estos patrimonios solo son ejemplos de la diversidad y el alto valor patrimonial de la provincia de Manabí. Fuente: Instituto Nacional de patrimonio cultural del Ecuador).

Figura 2: Casa de los Abuelos- Santa Ana. Fuente: Ministerio de Cultura y Patrimonio.

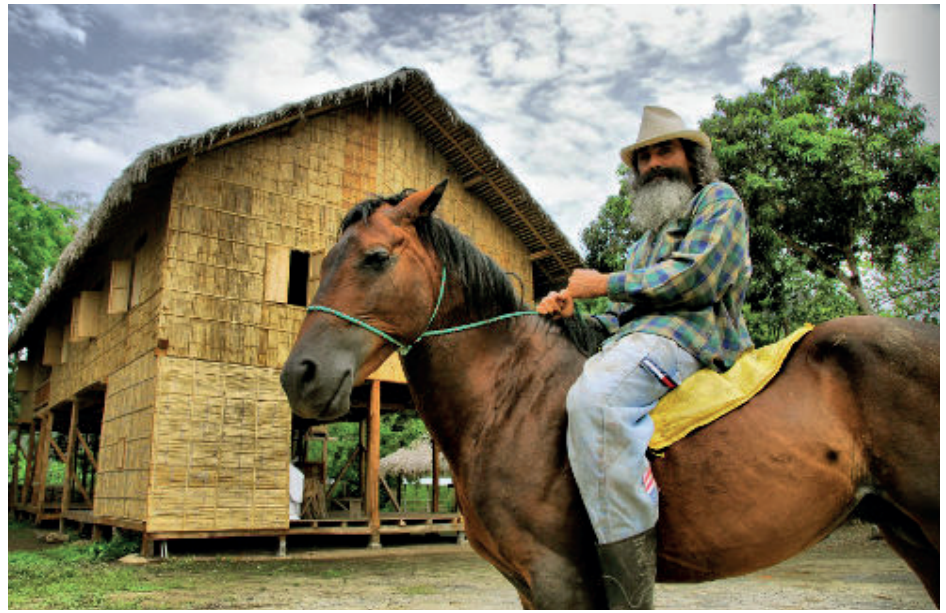

Tejido tradicional del sombreo ecuatoriano de paja toquilla.

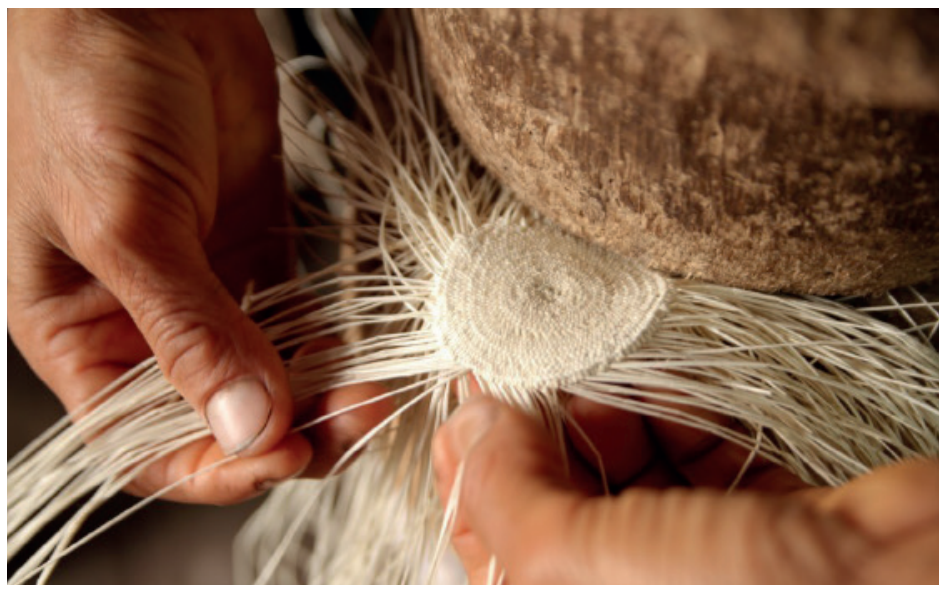

Fuente: Ministerio de Cultura y Patrimonio. 
Figura 3: Torre del reloj de la ciudad de Calceta.

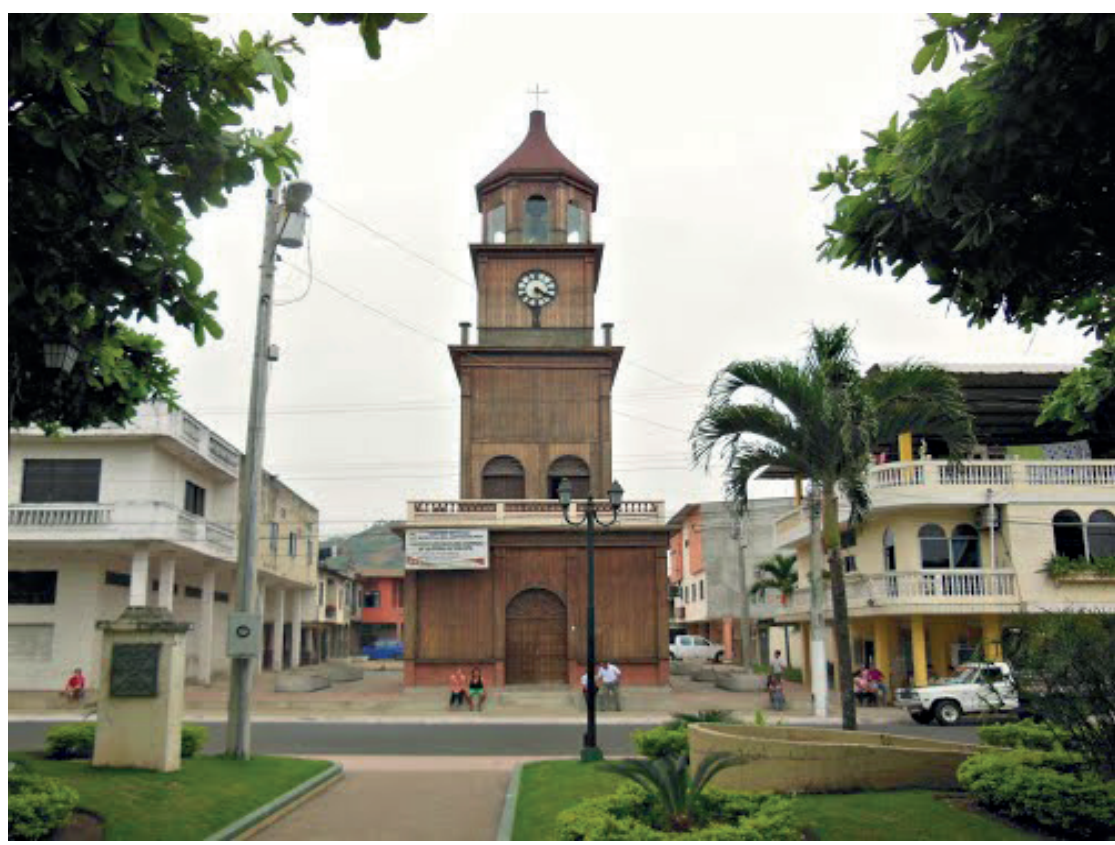

Fuente: Ministerio de Cultura y Patrimonio.

\subsection{Resultados de las encuestas aplicadas a cada una de las cuotas seleccionadas.}

A continuación se muestran los resultados de la encuesta realizada a los diferentes actores agrupados por cuotas: Comunicadores sociales (ComSoc), Promotores culturales (PromtCul), Funcionarios del turismo (FunTur) y Turistas (Turistas).

En la Figura 4 se muestran los resultados de las diferentes cuotas encuestadas respecto a: los servidores del turismo están comprometidos con los valores del legado cultural dejado por los abuelos.

Los comunicadores sociales consideran que los manabitas muestran valores y compromiso con el legado de hospitalidad y cultural que le dejaran los abuelos (64\%), también la mayoría de los turistas (78\%) perciben que los manabitas se sienten comprometidos con su legado cultural y con el servicio que brindan, en tanto que los funcionarios del turismo consideran que ese nivel de compromiso no es suficiente (solo el 56\% afirma percibir compromiso de los manabitas) para desempeñar con calidad su servicio. En cambio los promotores culturales se muestran desacuerdo (38\% indecisos y el $28 \%$ en desacuerdo) con que los manabitas valoren adecuadamente su legado cultural.

En la Figura 5 se muestran los resultados de las diferentes cuotas encuestadas, referente a: El servicio que se recibe se corresponde con el servicio promocionado.

Los turistas (36\% casi siempre y 33\% usualmente sí) perciben correspondencia del servicio promocionado con el recibido, al igual que los Funcionarios del turismo (24\% casi siempre y $44 \%$ usualmente sí), actores estos más cercanos al servicio turístico, sin embargo los comunicadores sociales (44\% ocasionalmente) y los promotores culturales con igual porciento perciben ciertas discrepancias entre lo promocionado y lo percibido.

En la Figura 6 se muestran los resultados de las cuotas encuestadas referente a: es importante la preparación de los servidores turísticos en temas de turismo cultural para desarrollar con calidad sus actividades.

En este punto, todos los actores participantes encuestados coinciden en significar la necesidad de capacitar a los servidores turísticos en temas de turismo cultural (Comunicadores sociales y promotores culturales $100 \%$ muy importante, funcionarios del turismo $75 \%$ muy importante y $16 \%$ importante, y los turistas $56 \%$ muy importante y $25 \%$ importante).

En la Figura 7 se muestran los resultados de las cuotas encuestadas referente a: los turistas manifiestan interés por consumir productos de turismo cultural. 
El 88\% de los funcionarios del turismo manifiestan que los turistas frecuentemente se interesan en los productos culturales de la provincia, lo que se corresponde con lo expresado por los turistas (80\% frecuentemente) busca consumir productos culturales. Sin embargo los promotores culturales creen (84\%) que solo ocasionalmente los turistas manifiestan interés en estos productos, criterio que aunque en menor grado (42\%), también es compartido por los comunicadores sociales.

En la Figura 8 se muestran los resultados de las cuotas encuestadas referente a: el turismo cultural forma parte de los productos turísticos que promociona el destino Manabí.

Como se observa en los resultados mostrados en la Figura 8, solo los Funcionarios del turismo (64\%) consideran que con frecuencia se encuentran los productos culturales en la promoción del producto Manabí. En contraposición los Promotores culturales (54\%), los comunicadores sociales (80\%) y loa turistas (54\%) perciben que los productos culturales de la provincia ocasional y raramente se encuentran como parte de la promoción del turismo manabita.

En la Figura 9 se muestran los resultados de las diferentes cuotas encuestadas referente a: la hospitalidad es una cualidad que distingue al manabita y a Manabí como destino turístico.

Los resultados evidencian que la hospitalidad distingue al turismo manabita los comunicadores sociales con el $100 \%$ de acuerdo, los promotores culturales con el $84 \%$, los funcionarios del turismo con el $84 \%$ y los turistas con el $81 \%$ así lo manifiestan.

En la figura 10 se muestran los resultados de las diferentes cuotas encuestadas referente a: Es importante la participación de los medios de comunicación locales y el sistema educativo en la promoción de los valores patrimoniales.

Todos los estratos encuestados coinciden en la necesidad de la participación de los medios de comunicación y del sistema educativo en la promoción de los valores patrimoniales de la provincia: Comunicadores sociales $80 \%$, Promotores culturales $64 \%$, Funcionarios del turismo 100\% y los turistas 78\%.

En la Figura 11 se muestran los resultados de las diferentes cuotas encuestadas referente a: se utilizan elementos de diseño de la arquitectura local en la infraestructura turística.

En cuanto a la presencia de la arquitectura local en las instalaciones turísticas, los comunicadores sociales expresan opiniones diferentes con cierta tendencia ( $32 \%$ ocasionalmente y $28 \%$ usualmente no) a poca utilización de la arquitectura, esta tendencia también es manifestada en las respuestas de los promotores culturales ( $36 \%$ ocasionalmente y $52 \%$ usualmente no). Sin embargo los funcionarios del turismo y los turistas opinan que si se utiliza la arquitectura local en las instalaciones turística pero no es suficiente ( $28 \%$ cree que solo ocasionalmente).

Como se observa en los resultados existe la percepción de que aún es escasa la utilización de los elementos arquitectónicos más representativos de la localidad, lo que pudiera en opinión de los autores de esta investigación convertirse en un elemento que agregaría valor a los productos turísticos de la provincia, fortaleciéndola como destino turístico.

En la figura 12 se muestran los resultados de las diferentes cuotas seleccionadas referente a: es importante la puesta en valor de patrimonio cultural para el desarrollo turístico de la provincia de Manabí.

Figura 12: Resultados de la pregunta 9 de la encuesta.

Todos los encuestados coinciden en su opinión respecto a la importancia que representa la puesta en valor de los valores patrimoniales culturales como atractivo para el desarrollo del turismo de cualquier destino. Este resultado se corresponde plenamente con lo manifestado en otras investigaciones tales como: Arista (2017), Hiriart y Barrera (2017).

\section{Resultados de la entrevistas}

\subsection{Resultados obtenidos en las entrevistas realizadas a los Administradores de empresas turísticas}

En el análisis de los resultados en cuanto a cómo evidenciar el compromiso en la atención al turistas se realiza a través del seguimiento que se le da al desempeño de los empleados, el cumplimiento de los indicadores establecidos en el reglamento interno y las referencias de los turistas y la participación en las actividades colectivas. Así como, el trato en igualdad de condiciones al turista sin importar apariencias o preferencias que este tenga. Los empleados son capacitados para que ofrezcan por igual un trato amable y personalizado al turista. Estos deben conocer los elementos básicos de la cultura del entorno, la geografía y los atractivos de la provincia y el país.

Para valorar el trato percibido por los turistas y el cumplimiento de la relación calidad precio, se toman como referencias el nivel de repitencia del turista, los comentarios positivos que se generan a 
través de las redes sociales. También en la atención personalizada se recogen sus opiniones y por los agradecimientos manifestados por diferentes vías, por las recomendaciones que hacen del servicio a amigos y conocidos, por el ranking que tiene el negocio.

Hay carencias en la orientación al turista y en la promoción de los valores culturales y patrimoniales de la provincia, lo que está relacionado en parte con el poco conocimiento de los elementos básicos del entorno: la cultura manteña, la geografía y los atractivos turísticos, costumbres ancestrales, eventos culturales y otros elementos que les permita incluso armar un plan de viaje a estos atractivos.

Los turistas se interesan en diferentes manifestaciones pero se les orienta poco, se reduce a mostrar los lugares donde se vende el sombrero de paja toquilla o los dulces de Rocafuerte, hay muchas otras cosas. El turismo cultural no es promocionado adecuadamente, está recién comenzando a incluirse en la carpeta de atractivos de Manabí, lo más promocionado de la cultura manabita es la gastronomía.

No existe un plan promocional por parte de las autoridades de la provincia para el desarrollo del turismo cultural. No hay apoyo de las autoridades y de los medios de comunicación para el desarrollo y promoción del turismo cultural y natural de la provincia.

En los proyectos deben estar encaminados en primer lugar a distinguir el destino Manabí con elementos como por ejemplo un símbolo gastronómico que identifique la ciudad de Manta.

Potenciar los festivales gastronómicos y de otras manifestaciones de la cultura debe ser uno de los objetivos de la planificación para el desarrollo del turismo cultural en la provincia.

Y no pueden faltar proyectos encaminados a la capacitación y educación no solo del personal involucrado en los servicios turísticos sino también en la población en general y con énfasis en la nueva generación para que no se pierdan las costumbres y valores ancestrales, que distinguen a los manabitas.

\subsection{Resultados obtenidos en las entrevistas realizadas a los Historiadores y Comunicadores}

Los visitantes valoran ese legado heredado, en particular en el campo donde el civismo y las buenas costumbres se transmiten de generación en generación y los temas de conversación importantes son las historias y enseñanzas de los padres y abuelos. Hay una mezcla ciudad campo interesante, por ejemplo se sigue consumiendo la gastronomía basada en el plátano, maní, yuca y el maíz.

No se investiga lo suficiente, lo que se hace es solo basado en lo poco que saben. La capacitación también es insuficiente y no solo son los promotores culturales, sino todos los actores involucrados los que tienen que capacitarse.

Los sectores culturales están realizando trabajo de recuperación: la puesta en valor de los chigualos, como prácticas rurales, que se desarrollan en el mes de diciembre, cuando se espera la llegada del niño Dios, las familias y amigos se reúnen en una casa, el dueña invita y elige una pareja como padrinos para el niño, que deben asistir con sendos regalos, casi siempre son canastas de dulces y recuerdos para los invitados, se hacen rondas, se dicen versos (estrofas rimadas de 4 versos) al niño Dios y contrapuntos (uno manda un mensaje a través de un verso y otro lo responde), bailes (el baile del sombrerito, el baile de la iguana) y la música reflejada en canciones como: El pasillo Manabí (letra: Elías Cedeño Jerves y música de Francisco Paredes Herrera) y la Tejedora manabita (letra de Francisco del Castillo y música de Filemón Macías) son un claro ejemplo de ello, que si reflejan la identidad local y ancestral, pero son eventos casi domésticos, pequeños actos. Los grandes actos que realizan las organizaciones, insertan muchos elementos foráneos de la cultura, como artistas internacionales y la concurrencia es grande. Pero si vinieran los chigualos del monte de Portoviejo la presencia de la gente es menor.

Hay que reforzar la actividad cultural local con la participación activa de los ancianos de la comunidad y todos los actores involucrados. También los medios de comunicación deben contribuir con programas que tengan que ver con la identidad cultural en todas sus manifestaciones con un trabajo investigativo que permita mostrar lo más auténtico de la provincia y el país.

A pesar de tener un ancestro cultural del cual enorgullecerse, no se valoran adecuadamente sus elementos. Es ahí donde la educación y los medios de comunicación juegan su rol más importante en la recuperación de la oralidad y otras manifestaciones como los chigualos, las fiestas de San Pedro y San Pablo, la tejedura de paja toquilla, la hechura de los dulces, en la tejedura de las hamacas, los petates, de los sombreros de mocora, pero a un público limitado.

La oralidad y la literatura manabitas no son reconocidas lo suficiente dentro del sistema educativo nacional, los libros y textos escolares se hacen en la capital de la República, para ser consumidos en todo el país, resaltando mucho la cultura andina, muy poco de la Costa y de Manabí casi nada. Algo se cuenta del tejido del sombrero de paja toquilla por haber sido declarado patrimonio inmaterial nacional. 
En general no se reconocen los valores patrimoniales locales y el rol de los medios de comunicación no es suficiente.

Se recurre al tema de la hospitalidad, porque el manabita siempre ha sido comerciante y los comerciantes, navegantes y viajantes son amigables por naturaleza, siempre tratando de enamorar al cliente para venderle. Es una cualidad intrínseca en los manabitas.

No hay que cambiar nada a la gastronomía tradicional manabita, el camotillo frito (La página Web del Ministerio de Cultura y Patrimonio describe al plato como ancestral y criollo. "El camotillo es un pez nativo del Pacífico y las Costas ecuatorianas. La preparación de la fritura llega a América con los españoles").lo puedo comer gourmet en cualquier otro lugar del mundo, pero si estoy en Manabí quiero comerlo como se prepara aquí. Los sabores y la presentación deben ser como lo hacían nuestras madres. No se trata de mostrar las ollas, sino de degustar los sabores, el sabor es lo importante la olla está de más. Más que modernizarla se debe aprender o conocer cómo se prepara nuestra comida, hay mucho que enseñar. En la presentación si hay que mejorar, hay que hacer uso de la creatividad al momento de presentar un plato, siempre y cuando se respete la integridad de los ingredientes.

Sería extraordinario que los hoteles, restaurantes y centros de recreación ocuparan la caña guadúa, que bien trabajada es admirada. Aquí la vemos como sinónimo de pobreza no de vida. Hay que recuperar los adornos en las casas, las flores, el colorido para alegrar la vida del turista. Las abuelas alegraban las casas con jardines llenos de flores, eso las hizo optimistas, alegres.

Parte de la identidad cultural de Manabí, está relacionada con el nacimiento y la muerte: Bautizo, velorios, matrimonios, fiestas a santos, chigualos, procesiones, la adoración a la Virgen, lo que demuestra que la religiosidad es muy fuerte en Manabí. La Virgen de Monserrate es una tradición muy arraigada.

En Manabí se da mucho la medicina natural. El alcohol es mezclado con marihuana, huevo de cuchucho (pajarito que anida en la campiña), el veneno del alacrán, de culebra equis cura muchas dolencias. El aguardiente puro con hierbas para sanar los ojos, los espantos, mal aire, un trago de currincho (aguardiente) en la noche para no enfermarse del corazón y dormir tranquilo. En general el alcohol es muy empleado para curar enfermedades; para el hígado, el páncreas.

\subsection{Resultados obtenidos en las entrevistas a Ciudadanos ilustres}

El conocimiento y compromiso de los manabitas con los valores y manifestaciones culturales es una enseñanza no traducida en títulos sino en las buenas costumbres y en el buen desenvolvimiento con los demás. El manabita se distingue por su hospitalidad, la solidaridad y generosidad, el amor al terruño.

Se debe incorporar un poco más la historia ancestral, ciertos hechos relevantes que deben permanecer en el tiempo como un legado cultural. Por ejemplo; rescatar a ciertos héroes, hay muchas historias de vida que no se han narrado y de las que se puede aprender. Hay que renovar la danza, avanzar en el tiempo, presentar una imagen más moderna, con los colores que realmente distinguen a la cultura de Manabí. Hoy que investigar más y motivar a las jóvenes generaciones, educarlos en el amor a su tierra y a sus costumbres, en el valor de la palabra y el respeto. El conocimiento hace que crezca el compromiso, por ello se debe investigar el desarrollo de la cultura y las influencias extranjeras en su desarrollo para potenciar con toques de modernidad los valores ancestrales.

Es fundamental el papel del sistema de educación en un contexto de tendencias globalizadoras de la enseñanza. Ahí debe predominar la enseñanza de la cultura local, tradicional del Ecuador y Latinoamérica que están estrechamente ligadas, pero siempre partiendo de la cultura local sus danzas, personajes y costumbres. Se debe investigar más, recoger los saberes de los ancianos que son una fuente de consulta importante.

La hospitalidad distingue al manabita, su autenticidad y sus saberes históricos y culturales. Las visitas no se anunciaban y se disfrutaba mucho compartir la tertulia y se brindaba la mejor de las comidas. Hay que hacer que los jóvenes lean y se eduquen en estas costumbres, que rescaten la oralidad manabita, sus historias y relatos.

No se debe dejar que una tendencia gastronómica mundial invada las costumbres culinarias manabitas, hay que hacer distinguir la comida manabita por ser más sana y más rica. Los ingredientes bien cosechados, y bien elaborada, con los encantos que tiene y por ser más ecológica.

Volver a lo verde natural, cambiar el entorno gris que causa el cemento: la caña, el cadi, el balcón florido. Hay que fusionar lo moderno y lo ancestral en la cocina, sin perder la esencia de la originalidad. Se puede mezclar lo típico con lo moderno, pero siempre empeñados en brindar un servicio de mayor categoría. 
Las manifestaciones culturales que más se recuerdan están relacionadas en lo fundamental con las festividades religiosas: La fiesta de las Cruces en los barrios, La fiesta de la Santa Cruz, de San Pedro y San Pablo, la Fiesta de San José y Semana Santa. También los velorios en el mes de mayo.

Nuestros abuelos recurrían al aguardiente, al aguardiente alcanforado (Era como el menticol), que tenían ciertas virtudes terapéuticas y surtían efectos en la medicina tradicional y que con el tiempo la industria farmacéutica fue radicando todas esas tradiciones para incrustarlas en medicamentos. El aguardiente era preferido para diferentes usos terapéuticos.

\section{Análisis de los resultados de los instrumentos aplicados.}

Contrastando los resultados de los instrumentos aplicados en la investigación se realizan las reflexiones siguientes:

Existe en la provincia un basto legado de tradiciones y hospitalidad con una gastronomía deliciosa y diversa (Patrimonio cultural del ecuador desde el 18 de octubre del 2018) que distinguen la cultura manabita, que muestran con orgullo y compromiso, sin embargo no se han desarrollado investigaciones científicas y proyectos suficientes que permitan convertir el patrimonio cultural en mejores recursos turísticos para potenciar el desarrollo del turismo cultural y por ende el desarrollo local.

No todos los recursos culturales del patrimonio de la provincia se utilizan como atractivo en los servicios turísticos; además, existen tradiciones por rescatar, tanto en la gastronomía como en las bebidas y medicinas utilizadas por los ancestros manabitas. Por ejemplo el alcohol mezclado con marihuana, el huevo de cuchucho y el veneno del alacrán se encuentran entre los remedios que se han utilizado para curar diferentes malestares físicos. Las investigaciones y los proyectos también deben enfocarse en este objetivo.

En la infraestructura turística y en específico la de alojamiento, no se priorizan los estilos constructivos propio del territorio que identifican la arquitectura manabita, como otro elemento de identidad del destino. Se considera que volver a lo verde natural, cambiar el entorno gris que causa el cemento: la caña, el cadi, el balcón florido son algunos de los elementos a tener en cuenta en el desarrollo y presentación del producto turístico manabita en su conjunto.

Hacer distinguir la comida manabita por ser más sana y más sabrosa, elaborada con ingredientes bien cosechados, con sus encantos y particularidades y por ser más ecológica. Hay que fusionar lo moderno y lo ancestral en la empeñados en brindar un servicio de mayor categoría.

No cambiar nada a la gastronomía tradicional manabita, el visitante, el turista quiere degustarlo como se prepara aquí. Los sabores y la presentación deben ser como lo hacían nuestras madres. No se trata de mostrar las ollas, sino de degustar los sabores, el sabor es lo importante la olla está de más. Más que modernizarla se debe aprender o conocer cómo se prepara la comida manabita. En cuando a la presentación se considera que si hay que mejorar, hay que hacer uso de la creatividad al momento de presentar un plato, siempre y cuando se respete la integridad de los ingredientes.

La promoción de los recursos turísticos del patrimonio cultural es insuficiente y la preparación del personal involucrado en estos procesos no alcanza los niveles deseados, particularmente en el conocimiento del patrimonio cultural de la provincia y el país. No se aprecia una integración de las actividades que realizan los diferentes actores que intervienen en el proceso.

Los servicios turísticos según la percepción de los clientes y prestatarios son de buena calidad pero no se apoyan en la totalidad de los recursos patrimoniales de la cultura manabita, en el mejor de los casos se destaca la gastronomía. Hay que investigar y profundizar en las tradiciones culinarias para su puesta en valor. Todavía queda mucho por hacer para incorporar el patrimonio manabita a los servicios turísticos y desarrollar el turismo cultural.

Hay coincidencia en la necesidad de la puesta en valor de los recursos del patrimonio cultural para lograr el desarrollo integral del destino y fortalecer sus atractivos. Estos resultados se corresponden con otras investigaciones en la que se refiere que en la actualidad los recursos patrimoniales y en particular el patrimonio cultural, determinan el motivo del viaje (Arista, 2017), generan nuevos nichos de mercado (Hiriart y Barrera, 2017), y en el caso de Ecuador una de las mayores fortaleza del turismo es el manejo adecuado del patrimonio cultural (García Palacios, 2016). 


\section{Conclusiones}

La cultura tiene varias acepciones conceptuales, desde diferentes disciplinas y dentro de cada una de ellas presenta diferentes enfoques teóricos. Considerando el punto de vista antropológico, puede entender como las prácticas materiales y de significación, al mismo tiempo, de continua producción, reproducción y transformación de las estructuras materiales y de significación que organizan la acción humana. Es todo lo complejo que incluye el conocimiento, las creencias, el arte, la moral, el derecho, las costumbres y cualesquiera otros hábitos y capacidades adquiridos por el hombre como miembro de la sociedad. Es el conjunto de los rasgos distintivos, espirituales, materiales y afectivos que caracterizan una sociedad o grupo social. Es, en esencia, la expresión genuina del modo de vida de una comunidad o grupo social.

El patrimonio cultural, además de referente simbólico y seña de identidad de una sociedad, es una pieza relevante de la calidad y del atractivo del territorio. Por tanto, cultura, patrimonio y turismo deben manejarse de forma complementaria a la hora de perfilar proyectos de desarrollo territorial. Es una tarea compleja que en cualquier caso con voluntad política y adecuados mecanismos de concertación y gestión, es posible perfilar estrategias de desarrollo, donde la dimensión turística se integre razonablemente en los planes de gestión patrimonial, y la dimensión patrimonial en los de desarrollo turístico, para que en total armonía garantizar la sostenibilidad del turismo, a la vez que se conserva el patrimonio cultural.

Los valores patrimoniales de la cultura manabita, los turistas y los funcionarios del turismo consideran están presentes en las actividades turísticas, sin embargo es insuficiente su puesta en valor y promoción con estos fines, según el criterio de los promotores culturales. Las personalidades entrevistadas destacan que permanecen muchos elementos de las tradiciones manabitas por retomar y poner en valor, incluso dentro de la gastronomía que es el valor patrimonial más utilizado como recurso turístico en la provincia; asimismo predomina la poca utilización de los elementos de la arquitectura local tradicional en las instalaciones turísticas, lo que supone existen brechas para la investigación logre convertir el patrimonio cultural en un atractivo fundamental del destino turístico de Manabí.

El patrimonio manabita es rico y diverso, tanto en lo natural con sus hermosas playas y parajes naturales propios de la costa del mar Pacífico, como su cultura con alto valor patrimonial e innumerables manifestaciones que incluyen entre otros la gastronomía, danzas, museos, preparación y utilización de bebidas con diferentes fines, los eventos relacionados con el nacimiento y la muerte: bautizos y velorios, su arquitectura y en particular una hospitalidad auténtica que destaca como recurso patrimonial indiscutible de los manabitas. Es decir que existen todas las condiciones necesarias para que el patrimonio cultural se convierta en el mayor atractivo turístico de la provincia, sin embargo los resultados obtenidos indican que todavía no se integran los intereses de la gestión cultural y de la gestión turística para lograr ese fin, el cual es pertinente en tanto que se conserve y desarrolle el patrimonio cultural, se potencie el desarrollo local y se generen nuevos empleos y riquezas para la sociedad.

De acuerdo a los resultados obtenidos, en particular a criterio de los comunicadores sociales y los promotores culturales. así como las personalidades distinguidas de la provincia, se hace necesario desarrollar una investigación profunda y multidisciplinar que permita obtener estrategias que alineen los intereses de la gestión turística y la gestión del patrimonio cultural, a la vez que contribuya al involucramiento de los medios de comunicación y del sistema educativo de manera efectiva en la transmisión y desarrollo de los valores patrimoniales.

\section{Bibliografía}

Albarrán Periáñez, J.D. 2017. Políticas turísticas y urbanísticas en torno al Patrimonio cultural en la comarca de los pueblos blancos de Cádiz: análisis de los casos de Olvera y Sahara de la sierra. Cuadernos de Turismo, 40:13-43 DOI: http://dx.doi.org/10.6018/turismo.40.309601.

Arévalo, Javier 2010. El patrimonio como representación colectiva. La intangibilidad de los bienes culturales. Gazeta de Antropología. 26 (1). http://hdl.handle.net/10481/6799.

Arista Castillo, L. 2017. Turismo y gobernanza en la conservación del patrimonio rural de México. Armadillo de los infantes, San Luis Potosí. International Journal of Scientific Management and Tourism, 3 (1): 311-339. 
Azevedo Salomao, EM. 2015. Habitabilidad, memoria y patrimonio cultural. Reflexiones sobre la cultura purépecha Academia XXII, 6 (10): 53-63.

Barreiro, D. y Criado-Boado, F. 2015. Analizando el valor social de Altamira. Revista PH. 87:108-127.

Barrera Luna, R. 2013. El concepto de cultura: definiciones, debates y usos sociales. Revista Clasehistoria. No. 343.

Bucheli, M., Castillo, C. y Villareal, J. 2009. Medir el patrimonio cultural un desafío para la contabilidad. Cuadernos de Contabilidad. 10 (26):51-65.

Cartagena, C. 2017. Educación patrimonial, experiencias locales en dos museos escolares costeros, Valdivia, región de Los Ríos, Chile. Cuadernos del Instituto Nacional de Antropología y pensamiento latinoamericano- series especiales. 4(3):7-15.

Criado-Boado, F. y Barreiro, D. 2013. El Patrimonio era otra cosa. Estudios atacameños Arqueología y Antropología surandinas. 45: 5-18. http://www.redalyc.org/articulo.oa?id=31528519002

Erice, Teresa. 2017. La diversidad cultural en el tiempo, una histografía crítica del proceso de creación de paisajes antiguos en Asturias, España. TSAFIQUI. No 9. https://doi.org/10.29019/tsafiqui.v0i9.346

Escribano Velasco, C. 2010. Socialización, puesta en valor e interpretación para la gestión del Patrimonio cultural y natural a escala local. Revista Estudios del Patrimonio cultural. 4. https://dialnet.unirioja. es/servlet/articulo? codigo $=3280856$

García Palacios, C. 2016. Turismo comunitario en Ecuador: ¿Quo vadis? Estudios y Perspectivas en Turismo, 25 (4): 597-614.

Gómez-Ortiz, A., Oliva-Frangonillo, M., Selvá-Catarineu, M. y Salvador-Franch, F. 2010. El paisaje como valor patrimonial en los espacios protegidos: el caso del parque nacional de Sierra Nevada, España. Scripta Nova, revista electrónica de Geografía y Ciencias sociales. XIV (346). http://www. ub.es/geocrit/sn/sn-346.htm.

Hernández Ramírez, J. 2011. Los caminos del Patrimonio. Rutas turísticas e itinerario culturales. Revista Pasos. Rev. De turismo y Patrimonio Cultural. 9 (2): 225-236. DOI: http://doi.org/10.25145/j. pasos.2011.09.021.

Jokiletho, J. 2016. Valores patrimoniales y valoración. Revista Conversaciones. 2: 20-32.

Hiriart, C., Alvarado, I. 2013. Una reflexión sobre el modelo de turismo cultural en Morelia: escenarios y tendencias para consolidar un turismo cultural sustentable. Revista MEC-EDUPAZ, 3: 4-38.

Hiriart, C., Barrera, C. 2017. La funcionalidad turística como herramienta para impulsar la gestión sustentable y procesos de resilencia en las ciudades mexicanas patrimonio mundial: Morelia como experiencia práctica. International Journal of Scientific Management and Tourism, 3 (3): 273-312.

Molano, O.L. 2007. Identidad cultural un concepto que evoluciona. Revista Opera. 7: 69-84.

Molina Ruíz, J., Tudela Serrano, M.L. y Guillén Serrano, V. 2014. Potenciación del patrimonio natural, cultural y paisajístico con el diseño de itinerarios turísticos. Cuadernos de turismo. 34: 189-211.

Montero-Muradas, I. y Ojeda Rodríguez, J.R. 2014. Variables culturales como fortalezas y debilidades en el diagnóstico competitivo de los destinos turísticos. Cuadernos de turismo. 33: 251-270.

Mendes Zancheti, S. 2016. Reconsiderando la evaluación de los bienes culturales. Conversaciones. 2: 47-58.

Pastor Coello, M. 2014. Del deterioro del Patrimonio a su puesta en valor e inclusión en la planificación turística. El caso de Valladolid. Cuadernos de turismo. 34: 213-232.

Peña Gálves, P. 2010. Valoración del Patrimonio cultural en los Ríos. Una nueva mirada para el análisis y la gestión del Patrimonio cultural. Revista AUS. 8:4-7. http://mingaonline.uach.cl/pdf/aus/n8/art02.pdf.

Peña Palma, J.M. 2013. Valores sociales y valores patrimoniales: elementos para determinar la significación del patrimonio documental. Revista Biblioteca universitaria. 16 (1):33-45. DOI: http:// dx.doi.org/10.22201/dgb.0187750xp.2013.1.18

Ramos, D. 2017. Sobre el concepto de Patrimonio cultural. Mitos revista Cultural. 4(3).

Rodas, M., Ullauri, N., Sanmartín, I 2015. El Turismo Comunitario en el Ecuador: Una revisión de la literatura. RICIT, 9: 60 - 77

Sandoval Guerrero, Lidia K. 2017. Patrimonio cultural y turismo en el Ecuador vinculo indisoluble. TSAFIQUI. No 9. https://doi.org/10.29019/tsafiqui.v0i9.349

Solórzano Venegas, M. 2016. Patrimonio cultural arqueológico de la parroquia rural la Pila. Rehuso. 1 (1): 49-62.

Troitiño Torralba, Libertad 2012. Las ciudades patrimonio de la humanidad de la región turística de Madrid: niveles medios de funcionalidad y adecuación turística del patrimonio cultural. Papers de Turisme. 51: 109-131.

Troitiño Torralba, Libertad 2015. La dimensión turística del Patrimonio cultural de la ciudad de Lorca, Murcia, España. Cuadernos de turismo. 36: 389-414. DOI: http//dx.doi.org/10.6018/turismo.36.231061. 
Tudela Serrano, M.L., Bernabé Crespo, M.B y Molina Ruíz, J. 2015. Un acercamiento al patrimonio cultural en enclaves de calidad visual. Baterías militares de Cabo tiñoso (Cartagena Murcia). Cuadernos de Turismo. 36: 415-432. DOI: http://dx.doi.org/10.6018/turismo.36.231071

Vera Noriega, J.A. y Rodríguez Carvajal, C. K. 2009. La psicología social y el concepto de cultura. Psicología y Socidade. 21 (1):100-107. 